\title{
Shape of small opacities and lung function in coalworkers
}

\author{
A COCKCROFT, G BERRY, JE COTES, JP LYONS
}

\section{From the Medical Research Council Pneumoconiosis Unit, Llandough Hospital, Penarth, and Pneumoconiosis Medical Panel, Cardiff}

ABSTRACT Lung function and chest radiographs were reviewed in 357 coalworkers who had been referred from the CardiffPneumoconiosis Medical Panel. The chest films were read according to the 1980 ILO classification of radiographs by three experienced readers. An irregularity score, reflecting the shape of the small opacities, was derived from the readings and compared with the lung function variables. Men with higher irregularity scores had significant reductions in ventilatory capacity and gas transfer factor, with no change in total lung capacity, after age, height, profusion of small opacities, and smoking habit had been taken into account. The effects were present both in those with and in those without large opacities. The agreement between readers over the shape of opacities was almost as good as for their profusion. Men with rounded opacities had a lower gas transfer factor if they were predominantly of the "p" type. The results are consistent with those for a combination of emphysema and interstitial fibrosis, which has been found in coalworkers with irregular opacities.

The radiographic appearances currently accepted as typical of simple coalworkers' pneumoconiosis are those characterised by small rounded opacities scattered through both lung fields. ' Several authors have found no association between the profusion of these rounded opacities and changes in ventilatory capacity. ${ }^{2-4}$ Others have reported abnormalities of lung mechanics and frequency dependence of compliance ${ }^{5}$ and of pulmonary gas exchange and ventilation-perfusion matching ${ }^{6.9}$ in coalworkers but have not found these abnormalities to be related to the radiological category of profusion of rounded opacities. ${ }^{5-9}$ One study, however, found an increase in residual volume in coalworkers' pneumoconiosis that was related to increase in profusion of rounded opacities. ${ }^{10}$ Some coalworkers have small irregular opacities, as well as small rounded ones, on the chest radiograph. Some authors have reported poorer lung function in coalworkers with irregular opacities than in those with only rounded opacities..$^{11-13}$

In the present study the degree of irregularity of small opacities on the $x$-ray film was compared with lung function in a group of coalworkers. The analysis took into account the effects of other factors known, or thought likely, toaffect lung function - namely age, height, smoking habits, presence of large opacities, and overall profusion of small opacities. The film readings undertaken for the study were used to look at interobserver agreement of the three readers on the degree of irregularity of the small opacities.

Address for reprint requests: Dr A Cockcroft, Department of Medicine, Charing Cross Hospital, Fulham Palace Road, London W6 8RF.

\section{Methods}

Since 1965 the Cardiff Pneumoconiosis Medical Panel has referred men to the Medical Research Council Pneumoconiosis Unit for detailed lung function tests. Three hundred and fifty-seven of these men had radiographic and lung function data available from their first visit to the laboratory and were included in the study. Data from subsequent visits were not included. For each man age, height, and smoking history at the time of lung function testing were extracted from the records. The methods of lung function testing used at the Pneumoconiosis Unit during this period have been standard. ${ }^{14}$ The lung function variables comprised forced expiratory volume in one second $\left(\mathrm{FEV}_{1}\right)$, forced vital capacity (FVC), total lung capacity (TLC), residual volume (RV), gas transfer factor of the lung for carbon monoxide (TLCO), and gas transfer factor per unit lung volume $(\mathrm{KCO})$. The TLCand $\mathrm{RV}$ were measured by helium dilution and the TLCOand Kco by the single-breath method.

The 357 films were read independently in random order by a panel of three experienced readers, using the 1980 ILO classification of radiographs. ${ }^{15}$ In this classification the reader records the overall profusion of small opacities and then indicates their size and shape by means of a two-letter combination, the first letter representing the dominant type of opacity and the second letter the less frequent type of opacity. An irregularity score was derived from the size-shape readings for each film, only shape being taken into account. For each reader a score of 0-3 was possible. Rounded opacities in the first and second position in the combination scored 
0 , irregular opacities in the second position only scored 1 , irregular opacities in the first position only scored 2 , and irregular opacities in the first and second positions scored 3. The scores of the three readers were summed, giving an overall score of $0-9$. If one or two of the three readers did not record small opacities then the score was calculated from the readers who gave a reading and multiplied appropriately to give a three-reader score. The profusion of small opacities on the film was taken as the median of the profusions recorded by the three readers. The individual records of the three readers were used to examine the agreement between them in assessments of the degree of irregularity of the small opacities. The combined readings were used in the rest of the analyses.

The lung function variables were analysed by multiple regression to find out whether they were related to the irregularity score. Initially the regressions were on age, height, profusion of small opacities (expressed as dummy variables representing categories 0,1 , 2 , and 3 ), and irregularity score (dummy variables representing the groups $0-2,3-5$, and 6-9). Correction factors for age and height were obtained from the regressions and used in subsequent analyses. The other factors that were considered, in case they influenced the relationships, were smoking habit and the presence of large opacities. The results are presented as mean values of lung function variables, adjusted for age, height, and profusion of small opacities, at different levels of irregularity score. The associations were assessed for statistical significance by fitting a linear trend on irregularity score.

The effect of the size of rounded opacities was examined in the men whose films showed all, or nearly all, rounded opacities (overall irregularity score 0 or 1 ). The men with predominantly "p" opacities were compared with those with predominantly " $q$ " or " $r$ " opacities for values of TLCO and KCO. These lung function variables have previously been found to be related to the size of rounded opacities. ${ }^{16} 17$

\section{Results}

The overall characteristics of the 357 men, including their radiographic features, are given in table 1 . Most of the radiographs were recorded as category 2 or 3 for profusion of small opacities and about a quarter as showing category B or C complicated pneumoconiosis. Most of the men were smokers at the time of lung function testing.

There were 340 films for which all three readers recorded small opacities. The irregularity scores for these films, with the separate scores for the three readers, are shown in table 2. Except for the extremes, a given score can be produced in several ways. For example, a score of 3 could result if all three readers recorded rounded as the dominant type of opacity and irregular as the secondary type, if one reader recorded the opacities
Table 1 Characteristics of the 357 men

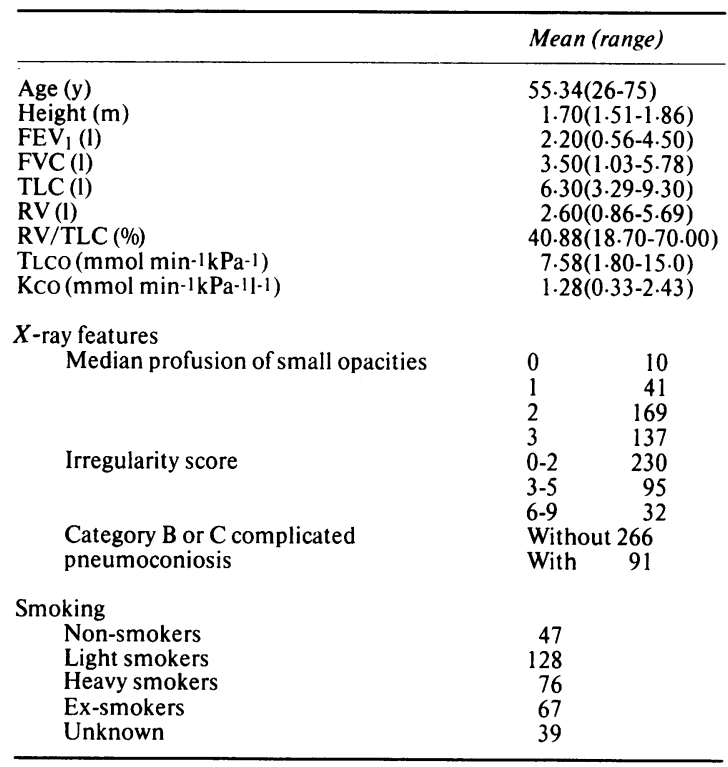

$\mathrm{FEV}_{1}$ - forced expiratory volume in one second; FVC - forced vital capacity; TLC - total lung capacity; RV - residual volume; TLCO - gas transfer factor; KCO - transfer coefficient.

as completely irregular and the other two readers as completely rounded; or if there was an intermediate situation. Table 2 shows that within a given score there was generally (score 6 is the only exception) a predominance of triplets with close agreement between the readers. There was significant evidence of agreement between readers although it was not as good as that for the major categories of profusion of small opacities. For irregularity $53 \%$ of the comparisons between any two of

Table 2 Contributions to the overall irregularity score by the three readers* showing the degree of agreement between them

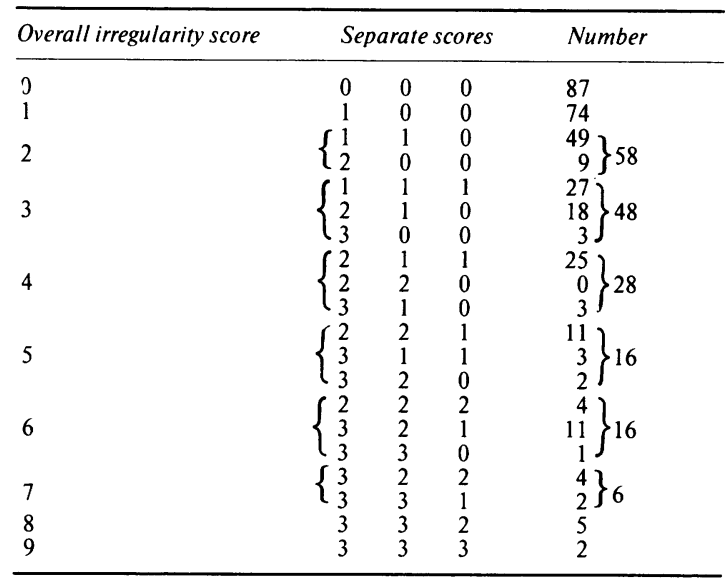

*Including only the 340 films for which all three readers recorded small opacities. 
Table 3 Relations between irregularity score and lung function variables

\begin{tabular}{|c|c|c|c|c|c|c|c|}
\hline $\begin{array}{l}\text { Irregularity } \\
\text { score }\end{array}$ & $\begin{array}{l}\text { Mean FEV } \\
\text { (l) }\end{array}$ & $\begin{array}{l}\text { Mean FVC } \\
\text { (l) }\end{array}$ & $\begin{array}{l}\text { Mean } T L C \\
\text { (l) }\end{array}$ & $\begin{array}{l}\text { Mean RV } \\
\text { (l) }\end{array}$ & $\begin{array}{l}\text { Mean } R V / T L C \\
(\%)\end{array}$ & $\begin{array}{l}\text { Mean TLCO } \\
(\mathrm{mmol} \text { min-lkPa-l) }\end{array}$ & $\begin{array}{l}\text { Mean KCO } \\
\left(\text { mmol min }-1 \mathrm{kPa}^{-1 /-l}\right)\end{array}$ \\
\hline $\begin{array}{l}0-2 \\
3-5 \\
6-9\end{array}$ & $\begin{array}{l}2.30 \\
2.04 \\
1.98\end{array}$ & $\begin{array}{l}3.54 \\
3.46 \\
3.33\end{array}$ & $\begin{array}{l}6 \cdot 26 \\
6 \cdot 38 \\
6 \cdot 37\end{array}$ & $\begin{array}{l}2.54 \\
2.68 \\
2.83\end{array}$ & $\begin{array}{l}40.2 \\
41.7 \\
42.9\end{array}$ & $\begin{array}{l}8.12 \\
7.00 \\
5.48\end{array}$ & $\begin{array}{l}1.37 \\
1.17 \\
0.99\end{array}$ \\
\hline Significance: $p^{*}$ & $<0.001$ & $>0.05$ & $>0.4$ & $<0.05$ & $<0.05$ & $<0.001$ & $<0.001$ \\
\hline
\end{tabular}

*From linear regression analysis; in the regression analysis and in calculations of the mean values of the lung function variables the effects of age, height, and profusion of small opacities were taken into account.

the readers agreed exactly and only $8 \%$ differed by two or more categories on the $0-3$ scale; the corresponding figures for profusion of small opacities were $59 \%$ and $2 \%$.

The irregularity score was significantly associated with several lung function variables, so that men whose films showed more irregular opacities had lower values of FEV, FVC, TLCO and KCO and higher values of RV and $\mathrm{RV} / \mathrm{TLC} \%$ than men whose films showed more rounded opacities (table 3 ). The values shown in table 3 take account of the effects of age, height, and profusion of small opacities. Age and height were shown to affect lung function as expected and the correction factors we produced were similar to those given by Cotes. ${ }^{14}$ Profusion of small opacities had relatively little effect on lung function. The $F E V_{1}$ was in fact significantly lower in men with category 0 profusion than in men with category 1-3 profusion. Moreover, the RV fell with increasing profusion. There was no significant association between irregularity score and profusion of small opacities (table 4).

The smoking history was available for 318 of the men, according to the categories of non-smoker, light smoker ( $<15$ cigarettes/day), heavy smoker ( $>15$ cigarettes/day), and ex-smoker. There was a significant association between smoking and irregular opacities, smokers having higher irregularity scores than non-smokers $(\mathrm{p}<0.02)$ (table 5). As expected, there were associations between smoking history and lung function variables. In particular, smokers had a lower FEV and TLCo than nonsmokers. The regression analysis to examine the effect of irregularity score on lung function was repeated for the 318 men for whom smoking history was available, to take smoking effects into account. There were no material changes in the associations between irregularity score and lung function when this was done.
Table 4 Irregularity score in relation to overall profusion of small opacities

\begin{tabular}{lccc}
\hline Profusion & \multicolumn{3}{l}{ Irregularity score } \\
\cline { 2 - 4 } & $0-2$ & $3-5$ & $6-9$ \\
\hline 0 & 6 & 3 & 1 \\
1 & 29 & 8 & 4 \\
2 & 110 & 47 & 12 \\
3 & 85 & 37 & 15 \\
\hline
\end{tabular}

Table 5 Smoking history in relation to irregularity score

Irregularity Non-smokers Light smokers Heavy smokers Ex-smokers score

\begin{tabular}{rrrrr}
\hline $0-2$ & 36 & 81 & 40 & 45 \\
$3-5$ & 10 & 31 & 26 & 19 \\
$6-9$ & 1 & 16 & 10 & 3 \\
\hline
\end{tabular}

The associations between irregularity score and lung function were re-examined separately in the men with and without category $\mathrm{B}$ or C complicated pneumoconiosis. The same trends in lung function (except for FVC) related to irregularity score were present in both groups, but were less prominent in the men with complicated penumoconiosis (table 6). Excluding these men did not alter the significance of any of the relationships between lung function and irregularity score found in the whole group of 357 men. The magnitude of the effect of complicated pneumoconiosis on ventilatory capacity and TLCO was less than that of the irregularity score effect.

In the men whose radiographs showed all, or nearly all, rounded opacities (irregularity score 0 or 1 ), those with predominantly " $p$ "opacities had significantly lower values of TLCO and KCO than those with predominantly "q" or " $r$ " opacities. The effect is shown in table 7. When

Table 6 Relationships between lung function and irregularity score in men with and without complicated pneumoconiosis

\begin{tabular}{|c|c|c|c|c|c|c|}
\hline $\begin{array}{l}\text { Irregularity } \\
\text { score }\end{array}$ & No & $\begin{array}{l}F E V_{l} \\
\text { (l) }\end{array}$ & $\begin{array}{l}F V C \\
\text { (l) }\end{array}$ & $\begin{array}{l}R V \\
\text { (l) }\end{array}$ & $\begin{array}{l}T L C O \\
(\mathrm{mmol} \text { min }-1 \mathrm{kPa}-1)\end{array}$ & $\begin{array}{l}K C O \\
(m m o l m i n-1 k P a-1 /-1)\end{array}$ \\
\hline \multicolumn{7}{|c|}{ Men without complicated pneumoconiosis } \\
\hline $0-2$ & 168 & 2.32 & 3.56 & 2.64 & 8.35 & 1.39 \\
\hline $3-5$ & 68 & 2.02 & 3.38 & 2.82 & 6.92 & 1.15 \\
\hline $6-9$ & 30 & 1.92 & 3.27 & 2.87 & 5.45 & 0.99 \\
\hline \multicolumn{7}{|c|}{ Men with complicated pneumoconiosis } \\
\hline $0-2$ & 62 & 2.23 & 3.49 & 2.26 & 7.44 & 1.32 \\
\hline $3-9 *$ & 29 & 2.07 & 3.64 & 2.38 & 7.07 & $\begin{array}{l}1.32 \\
1.19\end{array}$ \\
\hline
\end{tabular}

$\mathrm{FEV}_{1}$ - forced expiratory volume in one second; FVC - forced vital capacity; TLC - total lung capacity; RV - residual volume; TLCO - gas transfer factor; $\mathrm{KCO}$ - transfer coefficient.

*Only two of the men with complicated pneumoconiosis had irregularity scores in the range 6-9. Men with complicated pneumoconiosis are those in whom category B or C complicated pneumoconiosis was recorded by any reader. 
Table 7 Effect of size of rounded opacities on TLCo and KCO*

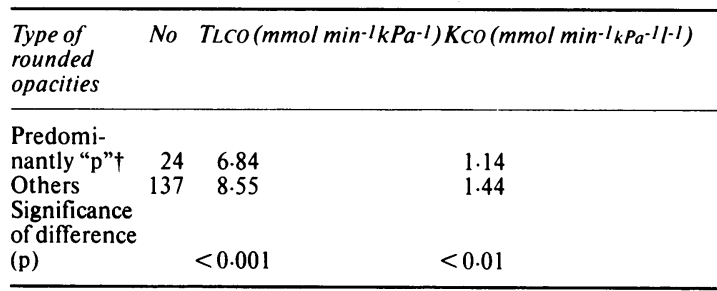

TLCO - gas transfer factor; KCO - transfer coefficient.

*Only $x$-ray films with irregularity scores 0 or 1 are included.

tMore " $p$ " than " $q$ " and " $r$ " combined over the three readers, where, as in the irregularity score, the first preference is given double the weight of the second.

the analysis was repeated taking smoking into account there were no material changes in these relationships.

\section{Discussion}

The results of this study support the findings of other workers. In a group of dead coalworkers those with irregular opacities present on the chest film during life were found to have had a lower FEV than those with only rounded opacities. " Similarly, in a large group of coalworkers the smokers with irregular opacities had a lower $\mathrm{FEV}_{1}$ than the smokers with only rounded opacities. ${ }^{12}$ Studies on South Wales coalworkers have found a lower gas transfer factor in those with irregular opacities than in those with only rounded opacities. ${ }^{13} 18$

There is postmortem evidence that coalworkers with irregular opacities have more emphysema and interstitial fibrosis, often in combination, than those with only rounded opacities. ${ }^{1113}$ The pattern of lung function impairment found in association with irregular opacities in the present study is consistent with a combination of emphysema and interstitial fibrosis. Both processes would produce a reduction in TLCO and KCO. RV would tend to be reduced in fibrosis and increased in emphysema; the increase found could result from a combination of the two processes. The lack of effect on TLC and the tendency for FEV ${ }_{1}$ and FVC to be affected to the same degree argue against emphysema as the only pathological condition associated with irregular opacities. Musk $e a^{18}$ found a reduction in gas transfer factor, no increase in compliance, and a tendency towards increased recoil pressure in coalworkers with irregular opacities, again suggesting some fib rosis coexisting with emphysema. Amandus et al found an increase in both TLC and RV in association with irregular opacities in working coalminers, ${ }^{12}$ suggesting that emphysema was the predominant associated pathological condition in their series.

The validity of associations with the shape of radiological opacities may be questioned if the agreement between readers about the shape of opacities is very poor. It is encouraging that, in this series at least, the disagreement between readers about shape was not much greater than about profusion. The main difference was that there seemed to be more films with major disagreement for shape than for profusion ( $8 \%$ versus $2 \%$ ). The strong associations between irregularity score and a logical pattern of lung function variables are also evidence that the score reflects a real condition that is associated with pathological changes affecting lung function.

The effects of several other variables on lung function were of interest. The general lack of effect of profusion of small opacities confirms previous findings. ${ }^{2-4}$ The men with category 0 profusion had a lower $\mathrm{FEV}_{1}$ than the men with category 1-3 profusion, possibly because men with normal films attend the Pneumoconiosis Medical Panel because they feel breathless whereas many of those with abnormal films are referred to the Pneumoconiosis Medical Panel simply because of the appearances. The presence of category B or C complicated disease produced a fall in RV and $T_{L C O}$, as is expected with a spaceoccupying lesion (table 6). The effect on TLCo was less prominent than that of irregular opacities. Smoking affected lung function as expected; but, although there was an association between smoking and irregular opacities, the effect of irregularity score on lung function was not materially changed by allowing for the smoking effect. Certainly in some cases irregular opacities may represent a smoking-related pathological condition in coalworkers, but this was clearly not their major cause in our group. In a study of working miners irregular opacities were associated with changes in lung function only in smokers, ${ }^{12}$ suggesting that smoking played a part in producing the lung function deficit associated with the irregular opacities.

It may be argued that the smoking histories used in the study could be inaccurate and that men applying to the Pneumoconiosis Medical Panel may tend to underestimate their smoking habits. This problem should not affect our results, however, since all our smoking histories were obtained in the same way and there is no reason to believe that those with irregular opacities would underestimate their smoking habits more than those with rounded opacities. Lifelong cigarette smoking may correlate better than current smoking habits with impairment in ventilatory capacity, but we did not use this index because of the difficulty in obtaining an accurate estimate from the Pneumoconiosis Medical Panel notes. Smoking histories were not available for $11 \%$ of our subjects because no record of them was made for a short time. There is no reason, however, to believe that there was an uneven selection of men with rounded or irregular opacities for the study during that period. When taking smoking into account we excluded men without smoking histories from the calculations, which did not alter relationships between 
irregularity score and lung function.

Previous work has shown that men with very small (" $p$ type") rounded opacities have a lower gas transfer factor ${ }^{16}{ }^{17}$ and more emphysema ${ }^{19}$ than men with "q" or "r" rounded opacities. Our results support this finding and indeed the effect on TLCO that we found was of a similar magnitude to that shown previously. ${ }^{17}$ The effect of size of rounded opacities was less than the effect of shape of opacities.

In the 1980 ILO classification of radiographs it is specified that the overall profusion of small opacities should be recorded; with the previous version of the classification the profusions of rounded and irregular opacities were recorded separately. The reasons for the change were specified ${ }^{15}$ but a consequence in our study was that it was impossible to allow for different effects of the profusions of the two types of opacity. As there was little association between the overall profusion and lung function, however, it is improbable that separate adjustments, had they been possible, would have made any material difference to our conclusions.

The probability that irregular opacities on the chest film in coalworkers are a real finding with associated effects on lung function must now be strong, tojudge by the results of this and previous studies. None of these studies, however, answers the important questions about how commonly these appearances occur in coalworkers generally and whether they can be considered to be part of coalworkers' pneumoconiosis. In this study the men were selected by being referred from the Pneumoconiosis Medical Panel for tests as well as by being seen by the panel. It was initially planned to refer preferentially men with irregular or " $p$ " type opacities. In practice, however, this does not seem to have happened since the proportion of men with irregular opacities in this study group was actually rather less than that in a group of men routinely reattending the Pneumoconiosis Medical Panel (unpublished data) and the proportion with " $p$ " opacities among those with rounded opacities was only $15 \%$ (see table 7 ). Thus our findings may be reasonably applicable to coalworkers attending the Pneumoconiosis Medical Panel in South Wales. Other work is under way to try to establish whether irregular opacities form an integral part of coalworkers' pneumoconiosis in those men in whom they occur.

We thank Dr JC Gilson, Dr G Sheers, and Dr PC Elmes, who undertook the $x$-ray readings; Mrs I Ashton, Mrs C Bevan, Miss C Heywood, and others at the MRC Pneumoconiosis Unit whose work made this study possible; and Miss C Squance at the Pneumoconiosis Medical Panel, who provided many of the records. Dr Cockcroft was funded by the Welsh Scheme for Development of Health and Social Research.
References

' Parkes WR. Occupational lung disorders. 2nd ed. London: Butterworths, 1982.

${ }^{2}$ Cochrane AL, Higgins ITT. Pulmonary ventilatory function in coalminers in various areas in relation to $x$-ray category of pneumoconiosis. Br J Prevent Soc Med 1961;15:1-11.

${ }^{3}$ Gilson JC, Hugh-Jones P, Oldham PD, Mead F. Lungfunction in coalworkers' pneumoconiosis. Medial Research Council Special Report Series No 290. London: HMSO,1955.

${ }^{4}$ Rogan JM, Attfield MD, Jacobsen M, Rae S, Walker DD, Walton WH. Role of dust in the working environment in the development of chronic bronchitis in British coal mines. $\mathrm{Br}$ J Indust Med 1973;30:217-26.

${ }^{5}$ Seaton A, Lapp NL, Morgan WKC. Lung mechanics and frequency dependence of compliance in coal miners. $J$ Clin Invest 1972;51:1203-11.

${ }^{6}$ James RH. Distribution of pulmonary ventilation in disabled south west Virginia coal miners. Am Rev Respir Dis 1970;101:715-20.

${ }^{7}$ Rasmussen DL, Nelson CW. Respiratory function in southern Appalachian coal miners. Am Rev Respir Dis 1971;103:240-8.

${ }^{8}$ Rasmussen DL. Patterns of physiological impairment in coalworkers' pneumoconiosis. Ann NY Acad Sci 1972;200:45564.

${ }^{9}$ Frans A, Veriter C, Brasseur L. Pulmonary diffusing capacity for carbon monoxide in simple coalworkers' pneumoconiosis. Bull Physiopath Respir 1975;11:479-502.

${ }^{10}$ Morgan WKC, Burgess DB, Lapp NL, Seaton A, Reger RB. Hyperinflation of the lung in coalminers. Thorax 1971;26:585-90.

11 Lyons JP, Ryder RC, Campbell H, Clarke WG, Gough J. Significance of irregular opacities in the radiology of coalworkers' pneumoconiosis. Br J Indust Med 1974;31:36-44.

12 Amandus HE, Lapp NL, Jacobsen G, Reger RB. Significance of irregular small opacities in radiographs of coalminers in the USA. BrJ Indust Med 1976;33:13-7.

${ }^{13}$ Cockcroft AE, Wagner JC, Seal RME, Lyons JP, Campbell MJ. Irregular opacities in coalworkers' pneumoconiosis correlation with pulmonary function and pathology. In: Walton WH, Critchlow A, eds. Inhaled particles ch 5. Ann Occup Hyg 26th, special ed (in press).

${ }^{14}$ Cotes JE. Lung function: assessment and application in medicine. 4th ed. Oxford: Blackwell Scientific Publications, 1979.

${ }^{15}$ International Labour Office. Classification of radiographs of the pneumoconioses. Geneva: ILO Publications, 1980.

${ }^{16}$ Lyons JP, Clarke WG, Hall AM, Cotes JE. Transfer factor (diffusing capacity) for the lung in simple pneumoconiosis of coalworkers. Br Med J 1967; iv:772-4.

${ }^{17}$ Cotes JE, Field GB. Lung gas exchange in simple pneumoconiosis of coalworkers. BrJ Indust Med 1972;29:268-73.

${ }_{18}$ Musk AW, Cotes JE, Bevan C, Campbell MJ. Relationship between type of simple coalworkers' pneumoconiosis and lung function. A nine-year follow-up study of subjects with small rounded opacities. Br J Indust Med 1981;38:313-20.

${ }^{19}$ Ryder R, Lyons JP, Campbell H, Gough J. Emphysema in coalworkers' pneumoconiosis. Br Med J 1970; iii:481-7. 